\title{
Zwitterion Surface-functionalized Thermoplastic Polyurethane for Antifouling Catheter Applications
}

\author{
Shantanu P. Nikam, ${ }^{\mathrm{a} \dagger}$ Peiru Chen, ${ }^{\mathrm{a} \dagger}$ Karissa Nettleton, ${ }^{\mathrm{a}}$ Yen-Hao Hsu, Matthew L. Becker ${ }^{\mathrm{b} *}$

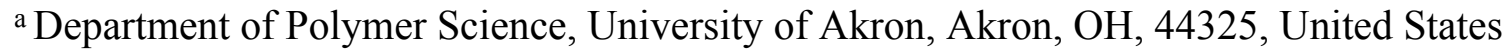 \\ ${ }^{b}$ Department of Chemistry, Mechanical Engineering and Materials Science, Orthopaedic \\ Surgery, and Biomedical Engineering, Duke University, Durham, NC, 27708, United States
}

$\dagger$ (Both authors contributed equally)

Figure S1. Thermoplastic polyurethane ${ }^{1} \mathrm{H}-\mathrm{NMR}$ spectra (Chloroform- $d$ )

Figure S2. ${ }^{1} \mathrm{H}-\mathrm{NMR}$ for 3,3'-dithioldiyldipropionyl chloride (Chloroform- $d$ )

Figure S3. ${ }^{13} \mathrm{C}-\mathrm{NMR}$ for 3,3'-dithioldiyldipropionyl chloride (Chloroform- $d$ )

Figure S4. ${ }^{1} \mathrm{H}$-NMR for bis(3-(dimethylamino)propyl) 3,3'-disulfanediyldipropionate (DMSO- $d_{6}$ )

Figure S5. ${ }^{13} \mathrm{C}$-NMR for bis(3-(dimethylamino)propyl) 3,3'-disulfanediyldipropionate (DMSO- $d_{6}$ )

Figure S6. ${ }^{1} \mathrm{H}-\mathrm{NMR}$ for 4,4,21,21-tetramethyl-9,16-dioxo-8,17-dioxa-12,13-dithia-4,21diazatetracosane-4,21-diium-1,24-disulfonate (zwitterion disulfide) $\left(\mathrm{D}_{2} \mathrm{O}\right)$

Figure S7. ${ }^{13}$ C-NMR for 4,4,21,21-tetramethyl-9,16-dioxo-8,17-dioxa-12,13-dithia-4,21diazatetracosane-4,21-diium-1,24-disulfonate (zwitterion disulfide) $\left(\mathrm{D}_{2} \mathrm{O}\right)$

Figure S8. ${ }^{1} \mathrm{H}-\mathrm{NMR}$ for 3-((3-((3-mercaptopropanoyl)oxy)propyl)dimethylammonio)propane-1sulfonate (zwitterion thiol) $\left(\mathrm{D}_{2} \mathrm{O}\right)$

Figure S9. ${ }^{13} \mathrm{C}-\mathrm{NMR}$ for 3-((3-((3-mercaptopropanoyl)oxy)propyl)dimethylammonio)propane-1sulfonate (zwitterion thiol) $\left(\mathrm{D}_{2} \mathrm{O}\right)$

Figure S10. ${ }^{13} \mathrm{C}-\mathrm{NMR}$ comparison for zwitterion thiol $\left(\mathrm{D}_{2} \mathrm{O}\right)$ and zwitterion disulfide

Scheme S1. lithium phenyl-2, 4, 6-trimethylbenzoylphosphinate (LAP) synthesis scheme

Figure S11. ${ }^{1} \mathrm{H}-\mathrm{NMR}$ for lithium phenyl-2, 4, 6-trimethylbenzoylphosphinate (LAP)

Figure S12. Model reaction ${ }^{1} \mathrm{H}-\mathrm{NMR}$ comparison before and after UV treatment

Figure S13. Representative fitting of ellipsometry curves

Figure S14. Representative contact angle images for Blank-TPU, Physical-TPU, zwitterion-TPU are shown.

Table S1. Contact angle results summary

Table S2. QCM measurement results summary

Table S3. Uniaxial Tensile Testing Summary

Table S4. Bacterial adhesion results summary

Table S5. Biomass accumulation results summary 

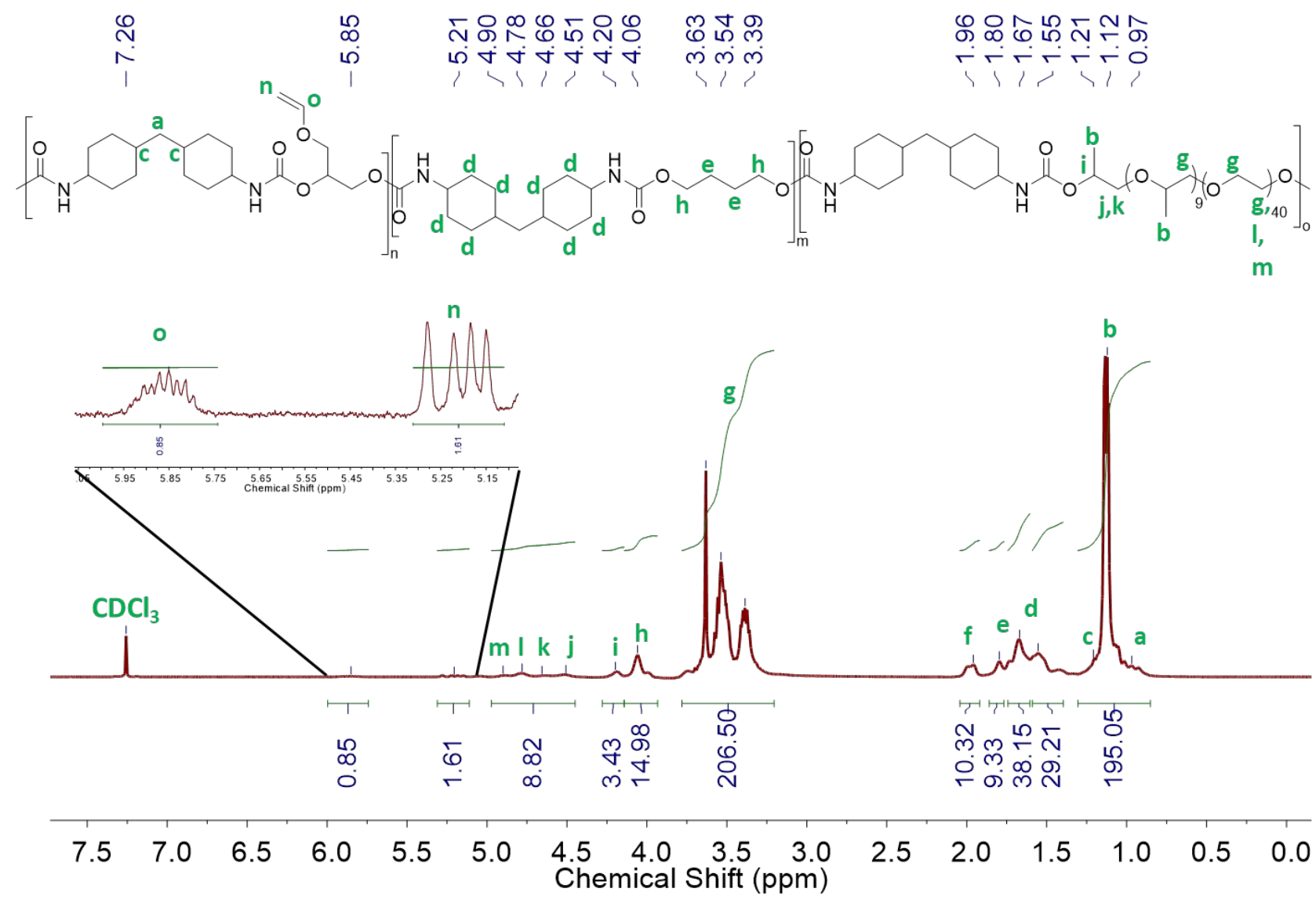

Figure S1. Thermoplastic polyurethane ${ }^{1} \mathrm{H}-\mathrm{NMR}$ spectra. The resonances $\boldsymbol{n}$ and $\boldsymbol{o}$ identified the allyl group in the side chain from 3-allyloxy-1,2-propanediol monomer. By integration, the allyl ratio in polymer can be determined $(\sim 15.7 \mathrm{~mol} \%)$. The resonances $\boldsymbol{g}$ and $\boldsymbol{b}$ confirmed the present of Arcol E-351 and its content. The resonances $\boldsymbol{e}$ and $\boldsymbol{h}$ confirmed the percentage of 1,4-butanediol. 


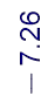<smiles>O=C(Cl)CCSSCCC(=O)Cl</smiles>

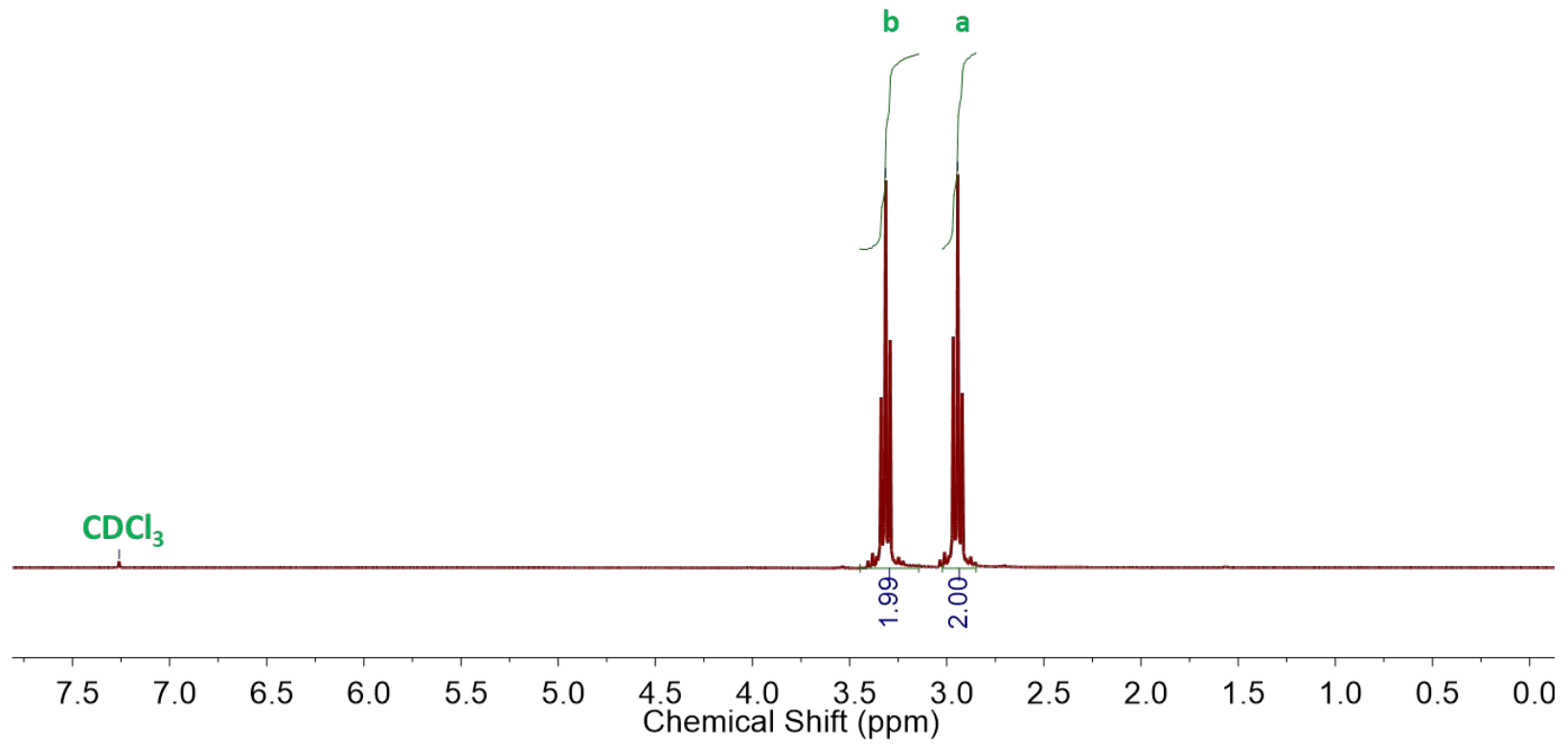

Figure S2. ${ }^{1} \mathrm{H}-\mathrm{NMR}$ for $3,3^{\prime}$-dithioldiyldipropionyl chloride ( $d$-Chloroform). Two triplet resonances, $\boldsymbol{a}$ and $\boldsymbol{b}$, are characteristic for disulfide bond in all the disulfide compounds synthesized in this paper. 

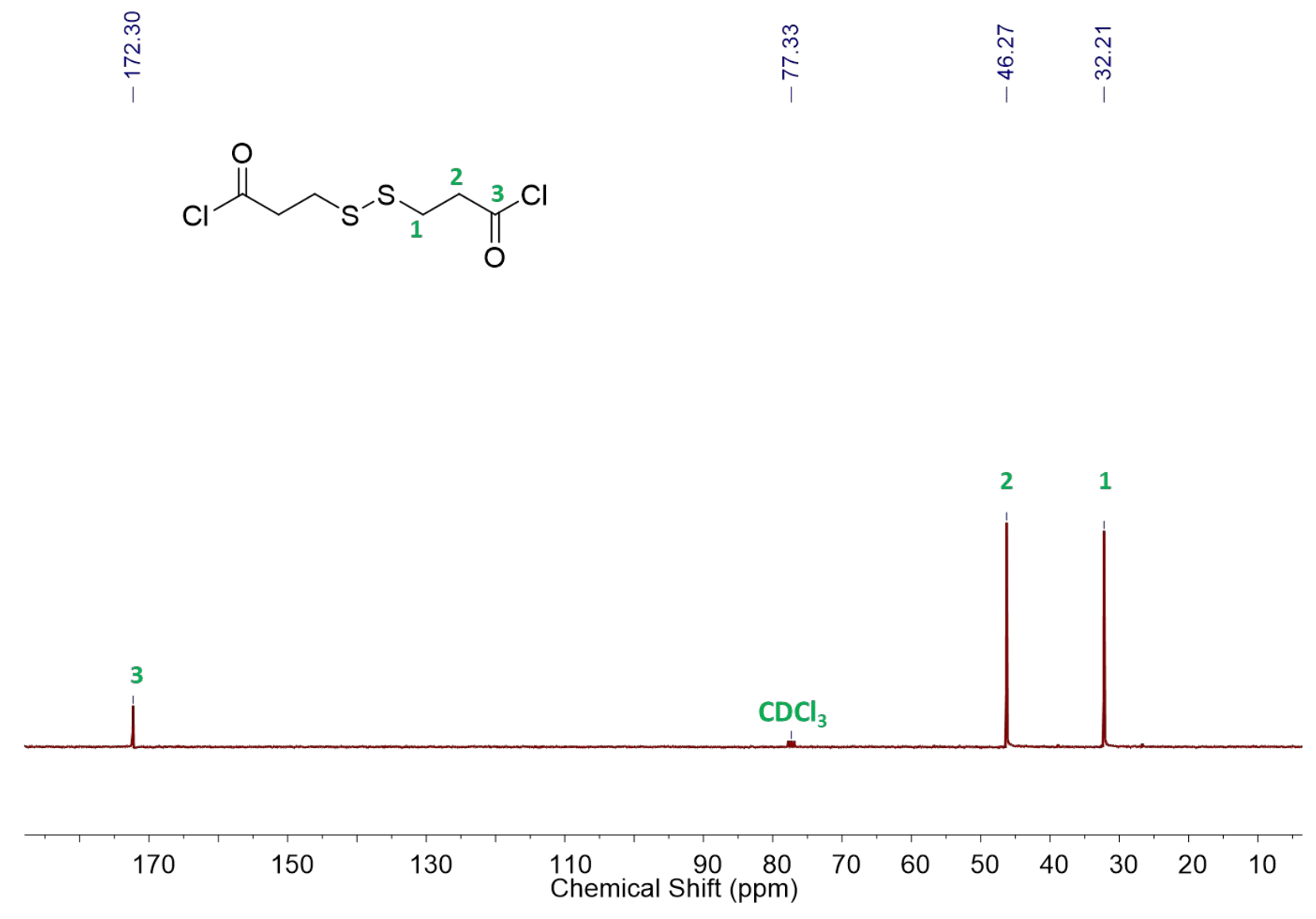

Figure S3. ${ }^{13} \mathrm{C}$-NMR for 3,3'-dithioldiyldipropionyl chloride ( $d$-Chloroform) confirms the purity of this compound. 


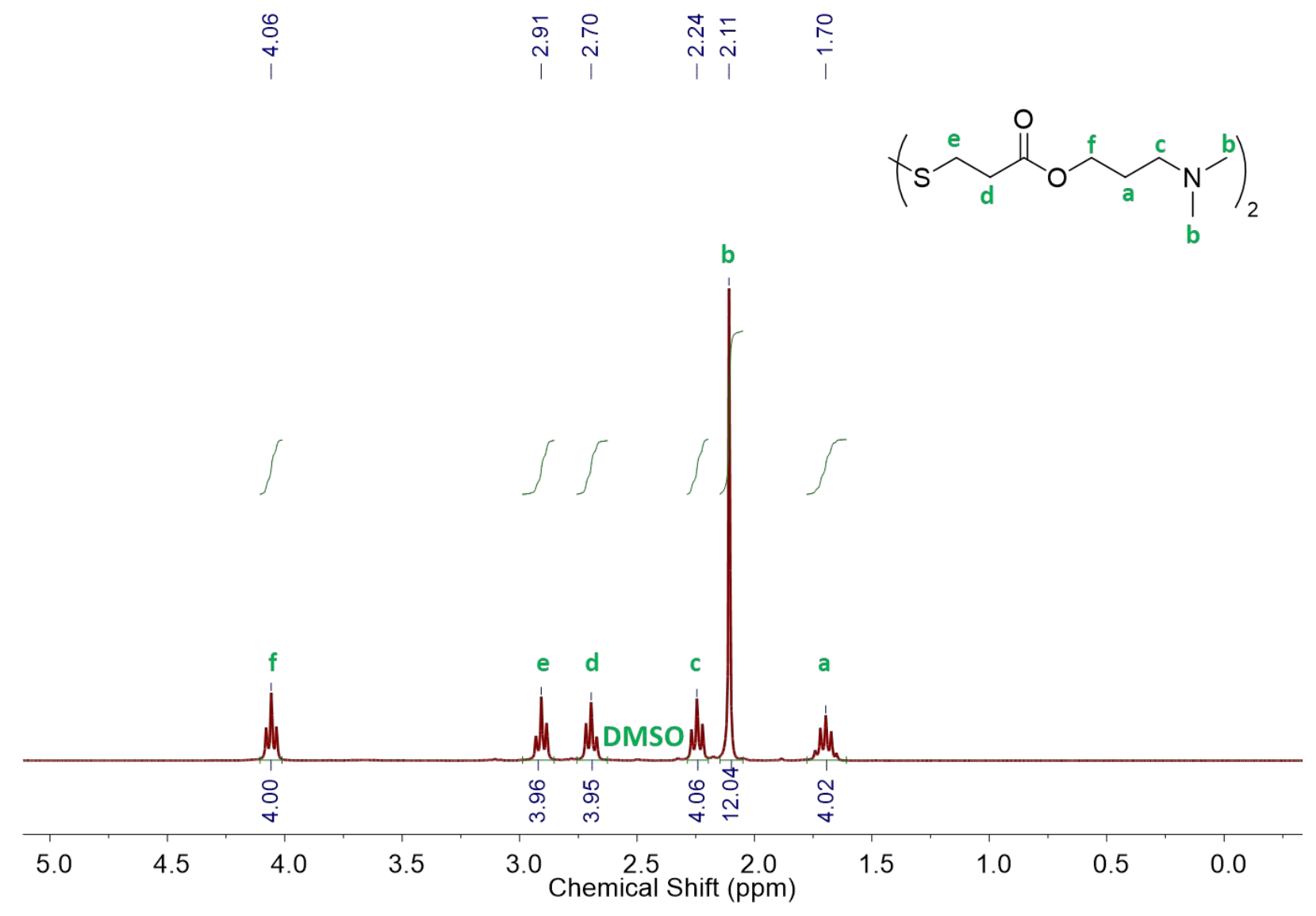

Figure S4. ${ }^{1} \mathrm{H}$-NMR for bis(3-(dimethylamino)propyl) 3,3'-disulfanediyldipropionate ( $d$-DMSO). Two triplet resonances $\boldsymbol{e}$ and $\boldsymbol{d}$ proved the existence of the disulfide bond. The singlet resonance $\boldsymbol{b}$ came from two methyl group in 3,3'-dimethylamino propanol. 


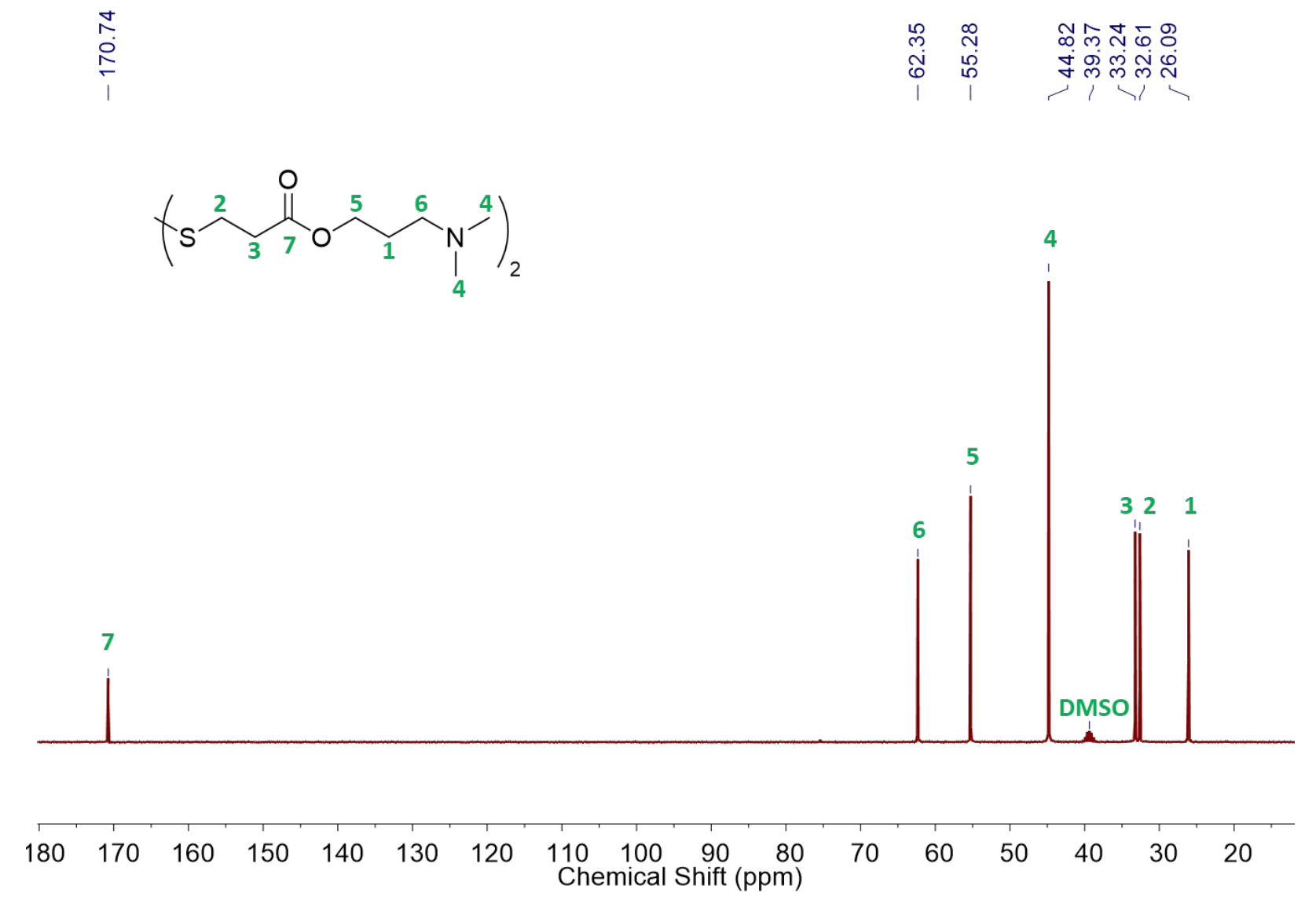

Figure S5. ${ }^{13} \mathrm{C}$-NMR for bis(3-(dimethylamino) propyl) 3,3'-disulfanediyldipropionate ( $d$-DMSO) indicates the purity of this compound. 


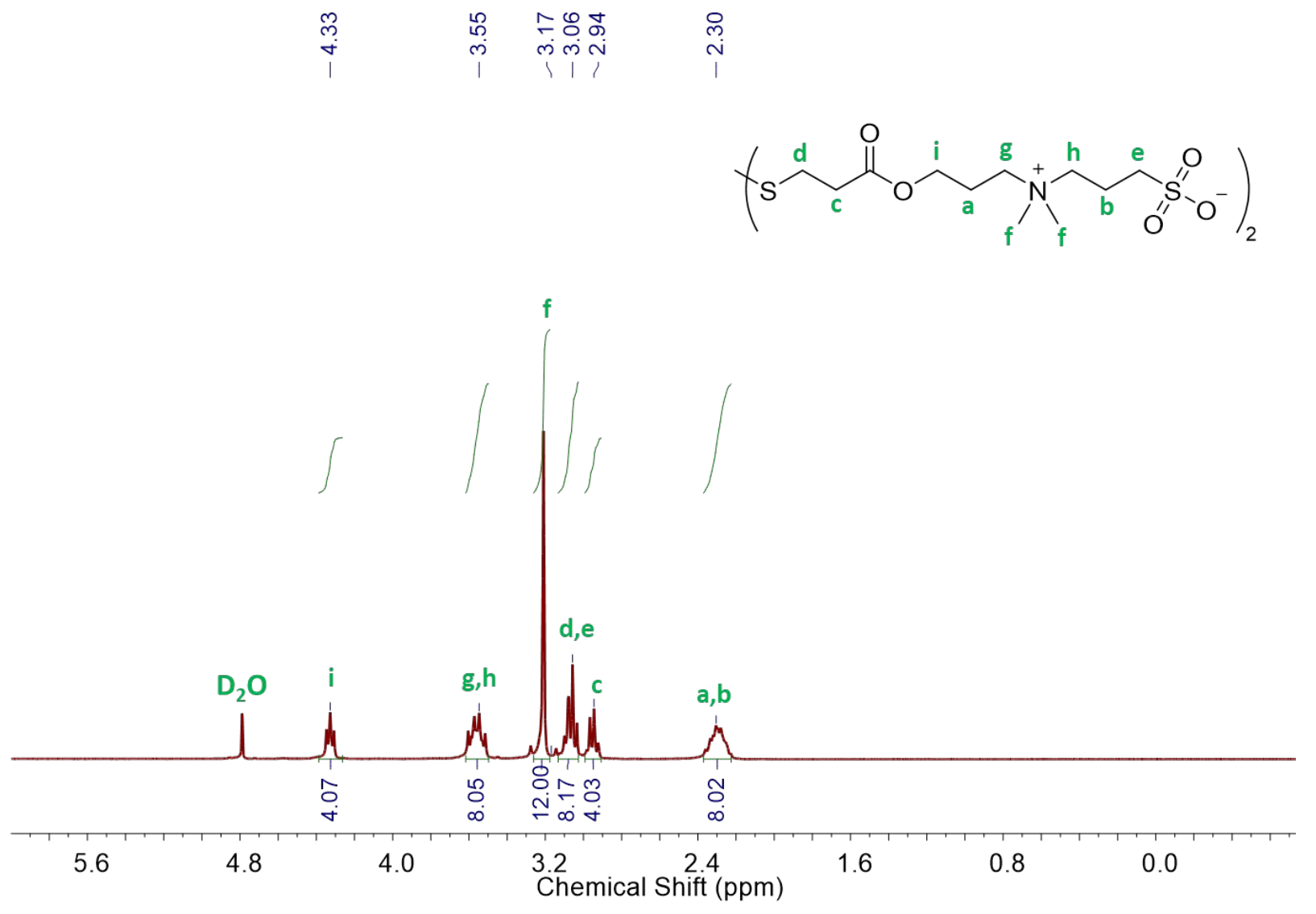

Figure S6. ${ }^{1}$ H-NMR for 4,4,21,21-tetramethyl-9,16-dioxo-8,17-dioxa-12,13-dithia-4,21diazatetracosane-4,21-diium-1,24-disulfonate (zwitterion disulfide) $\left(\mathrm{D}_{2} \mathrm{O}\right)$. New resonances from 1,3-propane sultone were formed (resonance $\boldsymbol{h}, \boldsymbol{b}$ and $\boldsymbol{e}$ ). The proton integration and chemical shift confirmed successful synthesis of the zwitterion disulfide compound. 

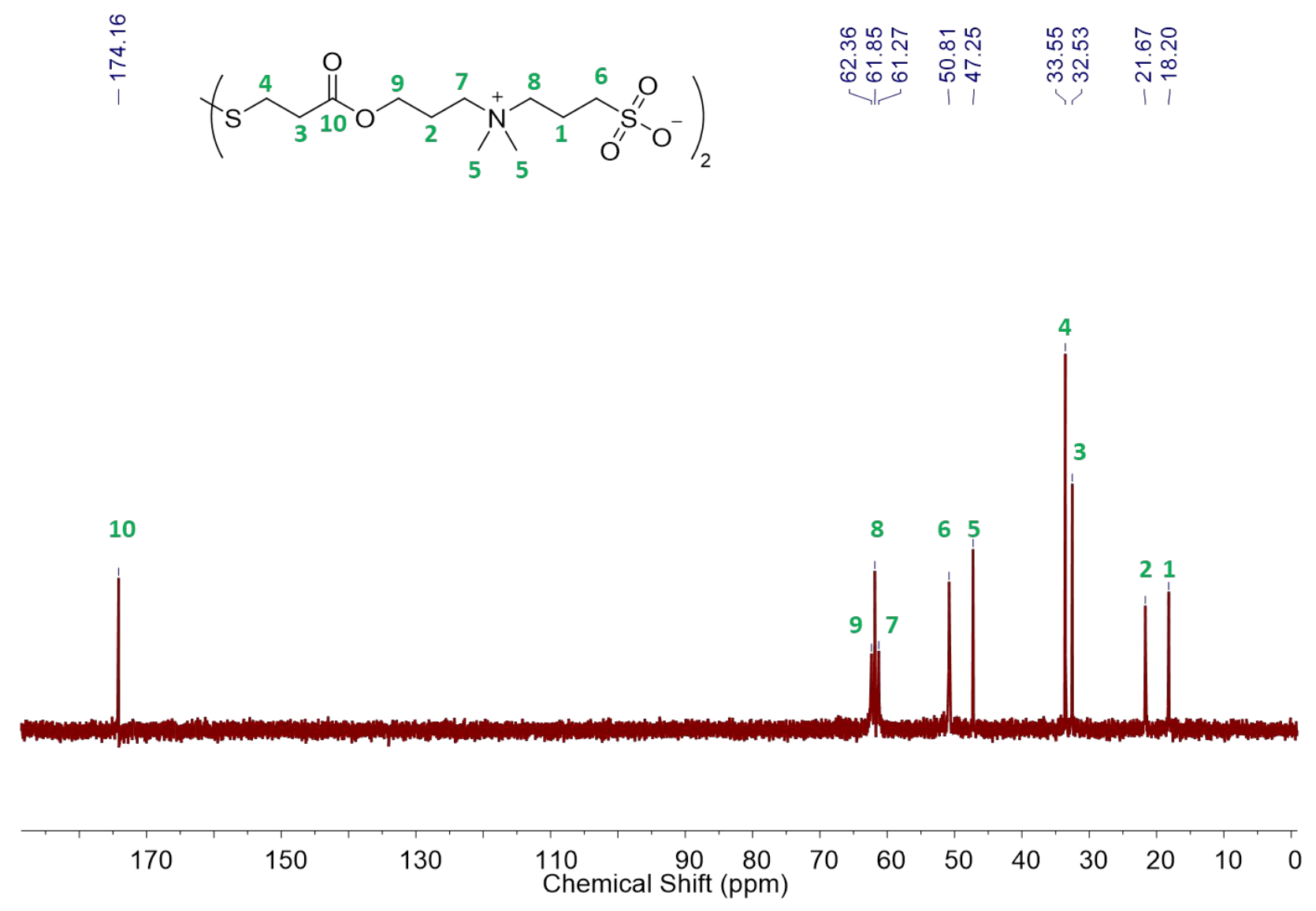

Figure S7. ${ }^{13}$ C-NMR for 4,4,21,21-tetramethyl-9,16-dioxo-8,17-dioxa-12,13-dithia-4,21diazatetracosane-4,21-diium-1,24-disulfonate (zwitterion disulfide) $\left(\mathrm{D}_{2} \mathrm{O}\right)$. Carbon NMR confirmed the purity of this compound. 


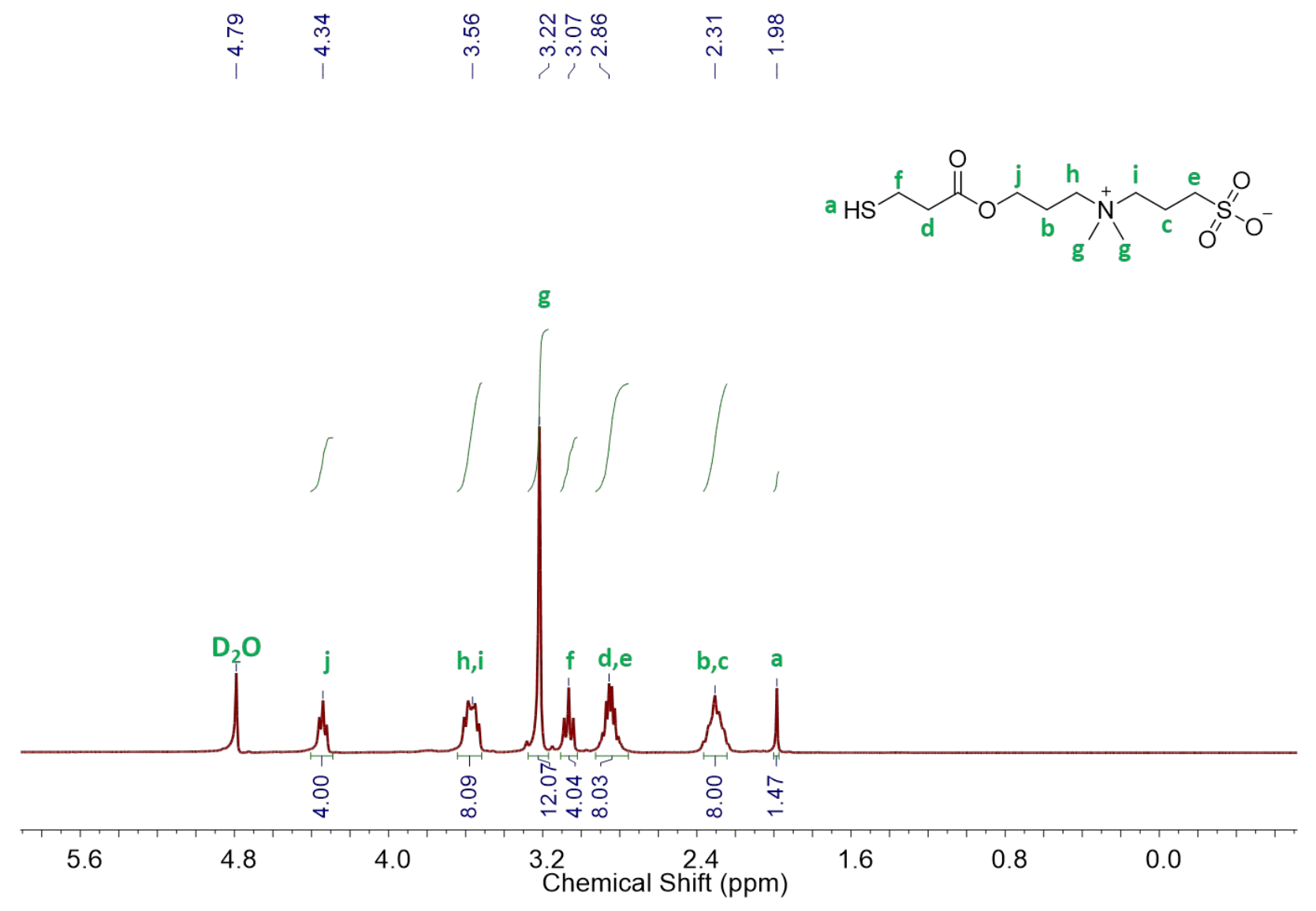

Figure S8. ${ }^{1} \mathrm{H}-\mathrm{NMR}$ for 3-((3-((3-mercaptopropanoyl)oxy)propyl)dimethylammonio)propane-1sulfonate (zwitterion thiol) $\left(\mathrm{D}_{2} \mathrm{O}\right)$. The resonances were almost identical to zwitterion disulfide, except a new resonance $\boldsymbol{a}$ showing at $1.99 \mathrm{ppm}$ corresponds to the proton attached to sulfur atom. 


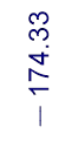

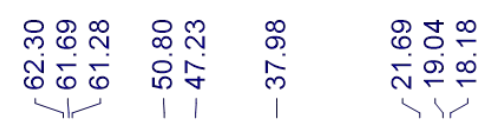
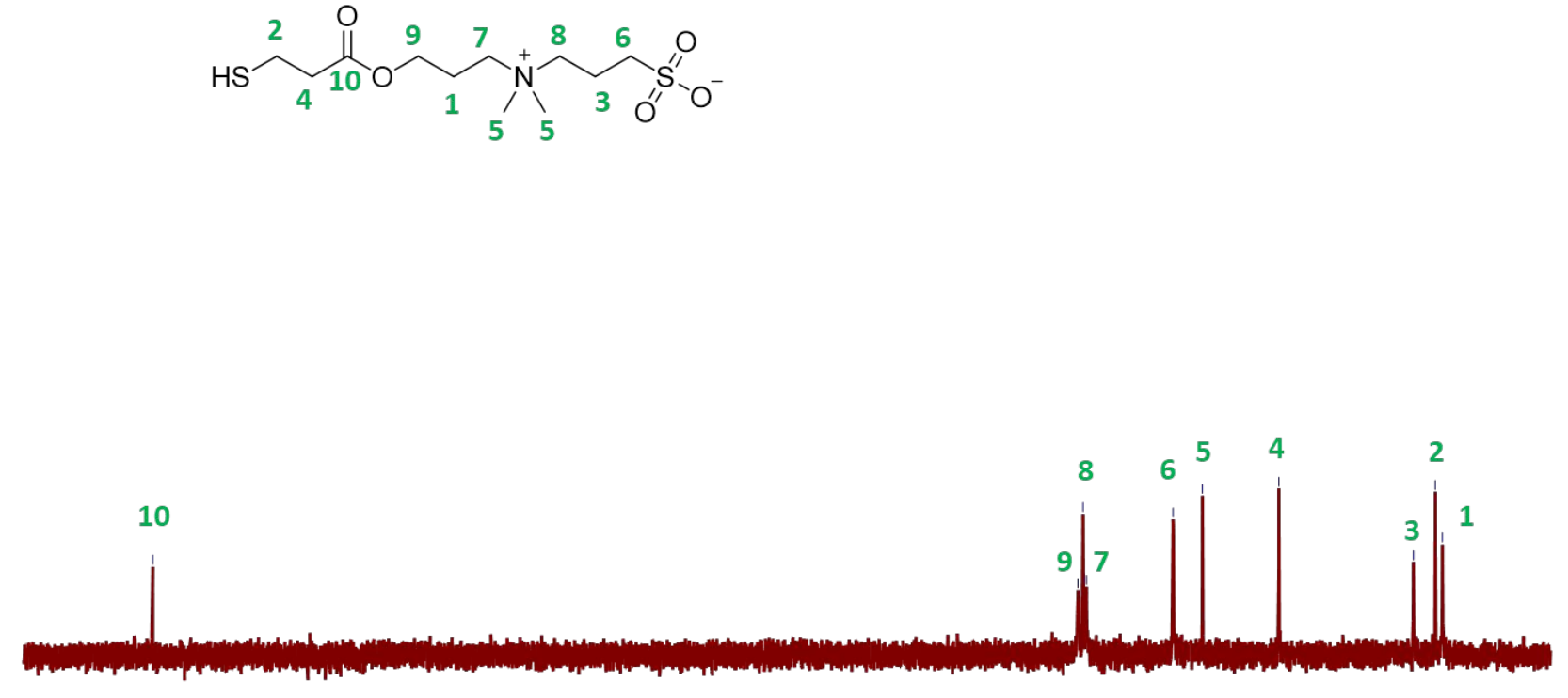

\begin{tabular}{llllllllllll}
\hline 170 & 150 & 130 & $\begin{array}{c}110 \\
\text { Chemical Shift (ppm) }\end{array}$ & 70 & 60 & 50 & 40 & 30 & 20 & 10
\end{tabular}

Figure S9. ${ }^{13} \mathrm{C}$-NMR for 3-((3-((3-mercaptopropanoyl)oxy)propyl)dimethylammonio)propane-1sulfonate (zwitterion thiol) $\left(\mathrm{D}_{2} \mathrm{O}\right)$. The purity of this zwitterion thiol was confirmed. 

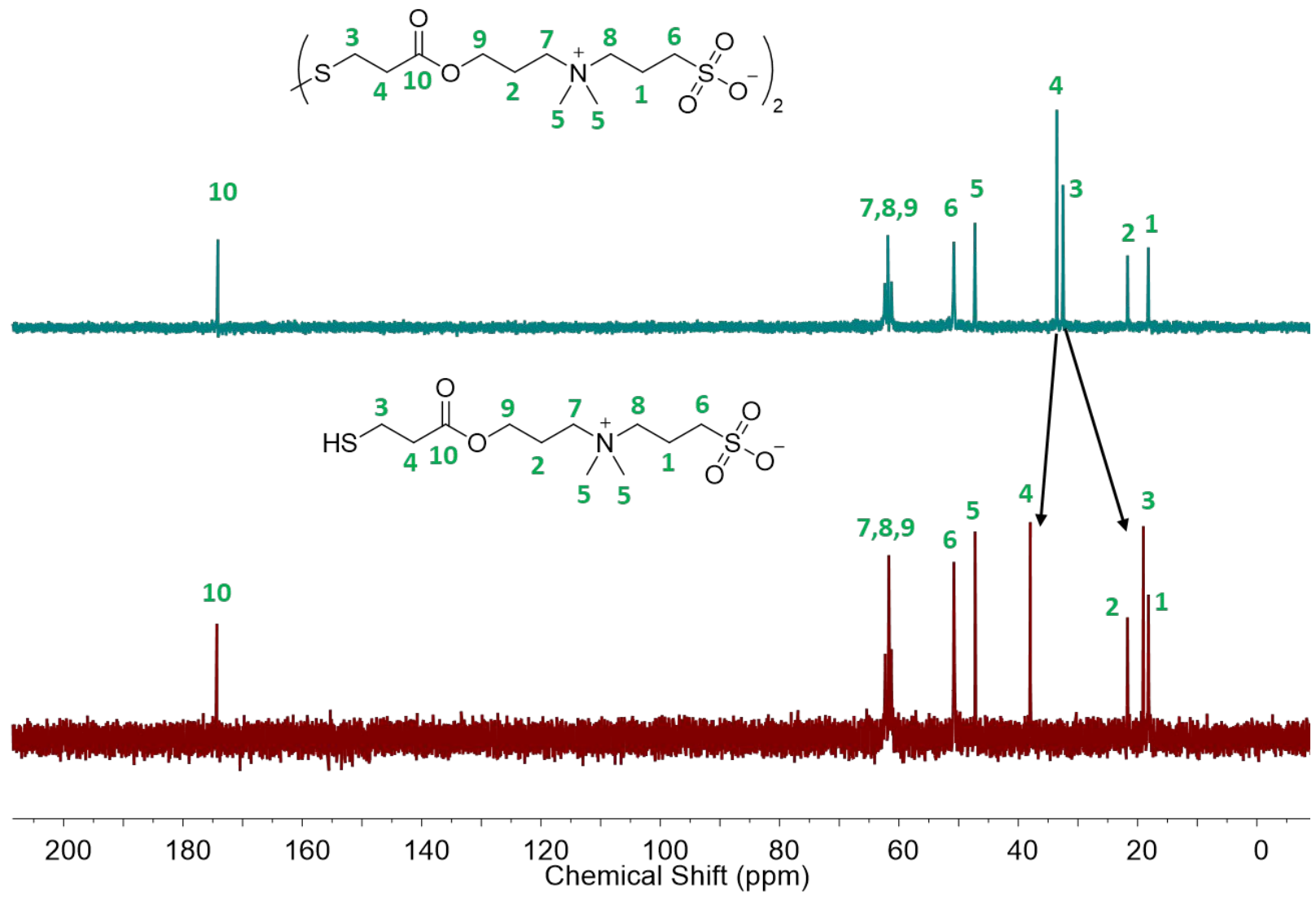

Figure S10. ${ }^{13} \mathrm{C}-\mathrm{NMR}$ comparison for zwitterion thiol $\left(\mathrm{D}_{2} \mathrm{O}\right)$ and zwitterion disulfide. The carbon 3 and 4 changed after disulfide cleavage demonstrate the successful disulfide reduction in this compound. 


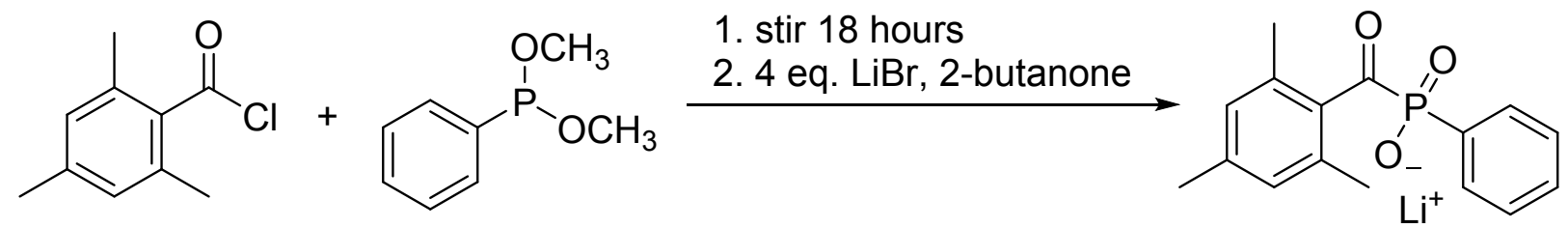

Scheme S1. Lithium phenyl-2, 4, 6-trimethylbenzoylphosphinate (LAP) synthesis scheme.

Synthesis of lithium phenyl-2,4,6-trimethylbenzoylphosphinate (LAP) photo initiator. At room temperature, $4.5 \mathrm{~mL}$ of 2,4,6-trimethylbenzoyl chloride (27.0 mmol, 1.0 eq.) was added dropwise into an equal molar continuously stirring dimethyl phenyl phosphonite $(4.3 \mathrm{~mL}, 27.0 \mathrm{mmol}, 1.0$ eq.). The mixture was allowed to stir at room temperature overnight. Following this, lithium bromide (9.37 g, $100.0 \mathrm{mmol}, 4.0$ eq.) in $120 \mathrm{~mL}$ of a 2-butanone solution was added into the reaction mixture and heated to $50{ }^{\circ} \mathrm{C}$. A white solid was formed after heating for $10 \mathrm{~min}$. The mixture was then allowed to cool to room temperature. The white solid was obtained after filtering and washed with 2-butanone to remove excess lithium bromide. The final product was placed under vacuum to remove residual solvent (92\% yield). The purity was confirmed by ${ }^{1} \mathrm{H}$ NMR (Figure S11).

${ }^{1} \mathrm{H}$ NMR $\left(300 \mathrm{MHz}, \mathrm{D}_{2} \mathrm{O}\right) \delta=7.70\left(\mathrm{dd},{ }^{3} J_{\mathrm{H}-\mathrm{H}}=11.2,8.3 \mathrm{~Hz}, 2 \mathrm{H}\right), 7.47\left(\mathrm{~d},{ }^{3} J_{\mathrm{H}-\mathrm{H}}=30.0 \mathrm{~Hz}\right.$, $3 \mathrm{H}), 6.84(\mathrm{~s}, 2 \mathrm{H}), 2.19(\mathrm{~s}, 3 \mathrm{H}), 2.00(\mathrm{~s}, 6 \mathrm{H})$. 


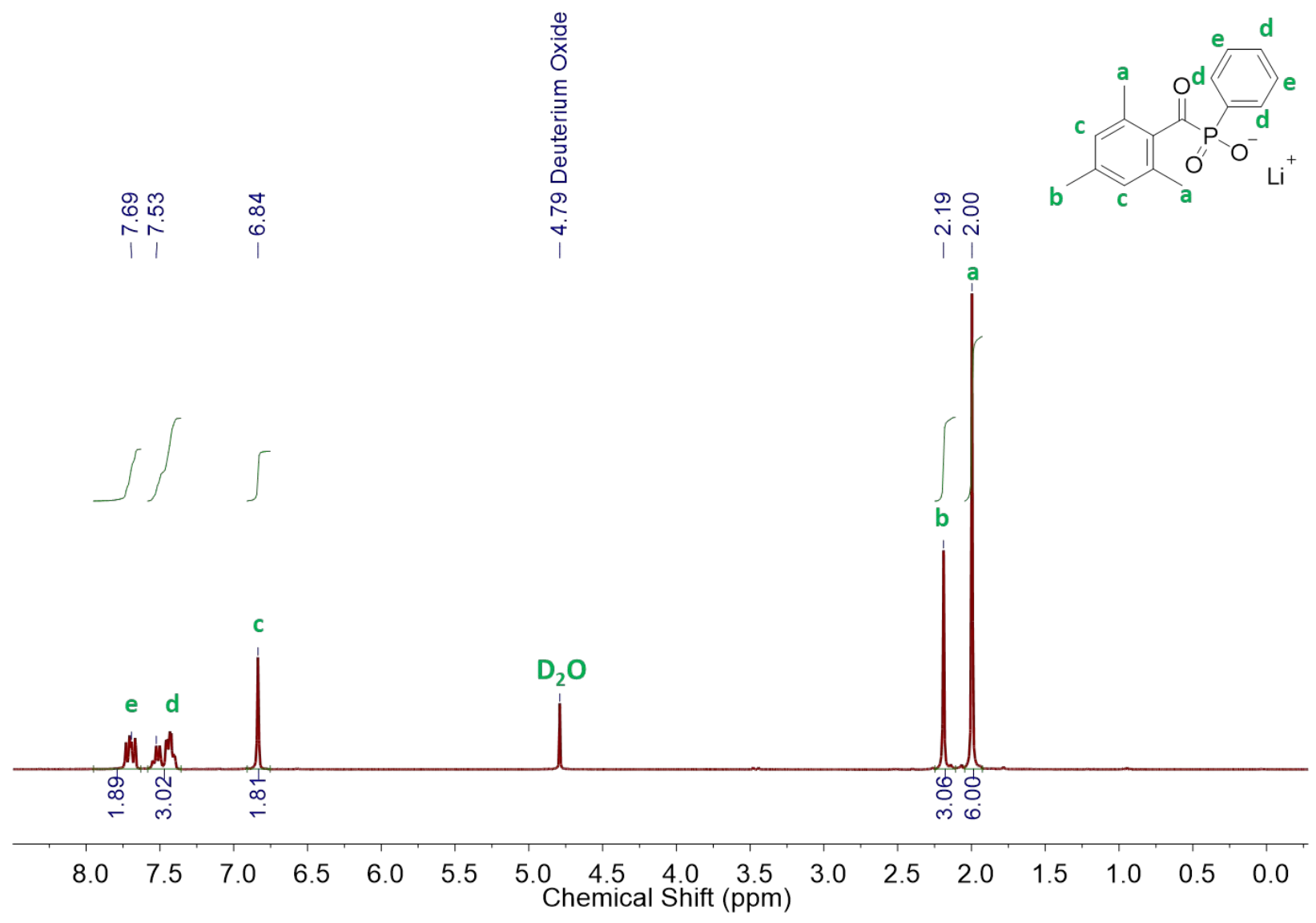

Figure S11. ${ }^{1} \mathrm{H}-\mathrm{NMR}$ for photo initiator, lithium phenyl-2, 4, 6-trimethylbenzoylphosphinate (LAP), indicates the purity of this compound. 

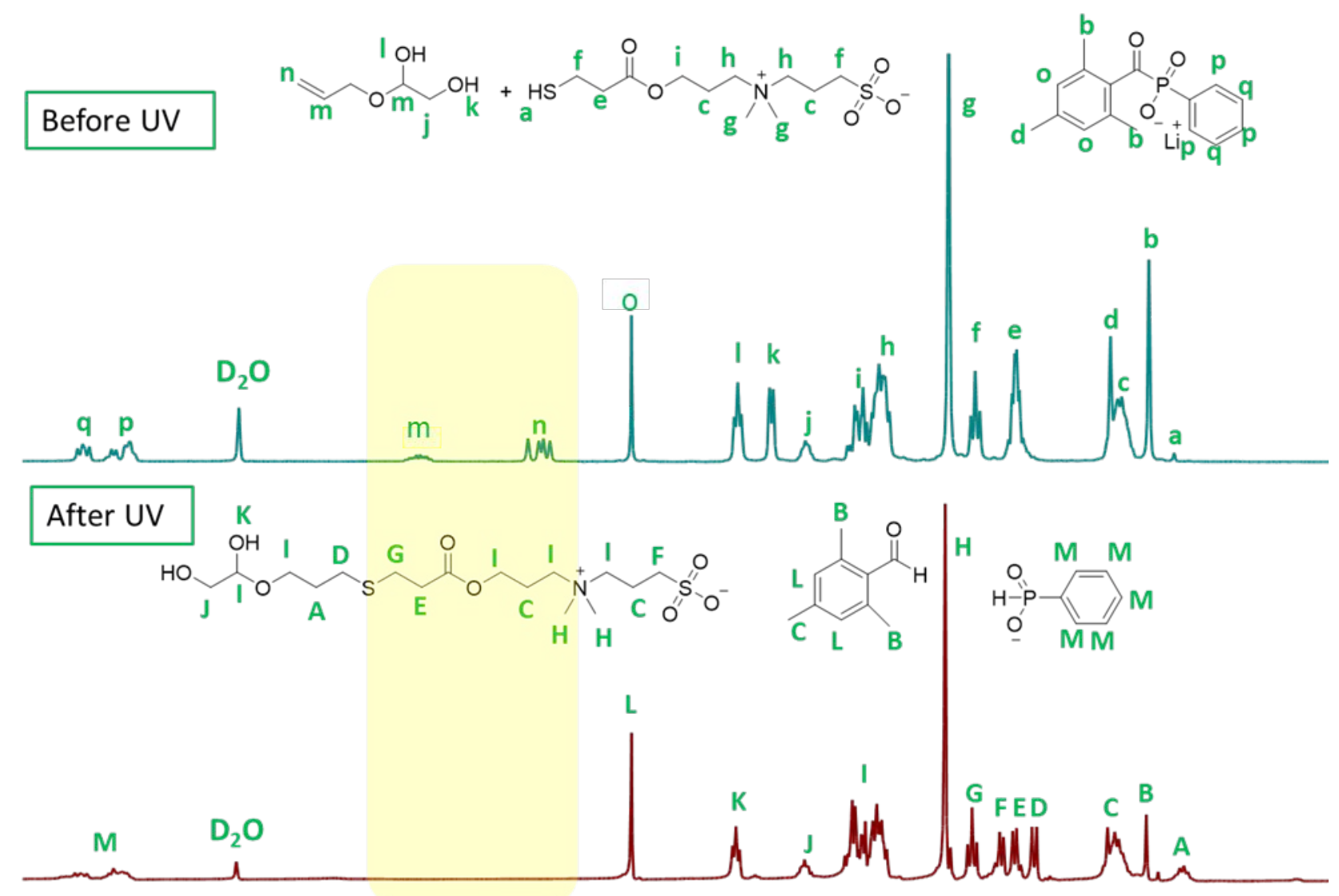

\begin{tabular}{llllllllllll}
\hline 8.0 & 7.5 & 7.0 & 6.5 & 6.0 & 5.5 & $\begin{array}{c}5.0 \\
\text { Chemical Shift } \underset{(\mathrm{ppm})}{4.0}\end{array}$ & 3.5 & 3.0 & 2.5 & 2.0 & 1.5
\end{tabular}

Figure S12. model reaction ${ }^{1} \mathrm{H}-\mathrm{NMR}$ comparison before and after UV treatment. The disappearance of resonance $\boldsymbol{n}$ and $\boldsymbol{m}$ shows the depletion of allyl group, and the aromatic resonance of photo initiator changed after UV exposure (resonances $\boldsymbol{q}$ and $\boldsymbol{p}$ changed to resonance $\mathbf{M}$ ) indicates the LAP underwent radical reaction to form thiol- ene products. New resonances from the thiol-ene reaction were found after UV treatment $(\boldsymbol{A}, \boldsymbol{D}$ and $\boldsymbol{I})$. This figure demonstrates the thiol-ene reaction with two compounds is successful. 

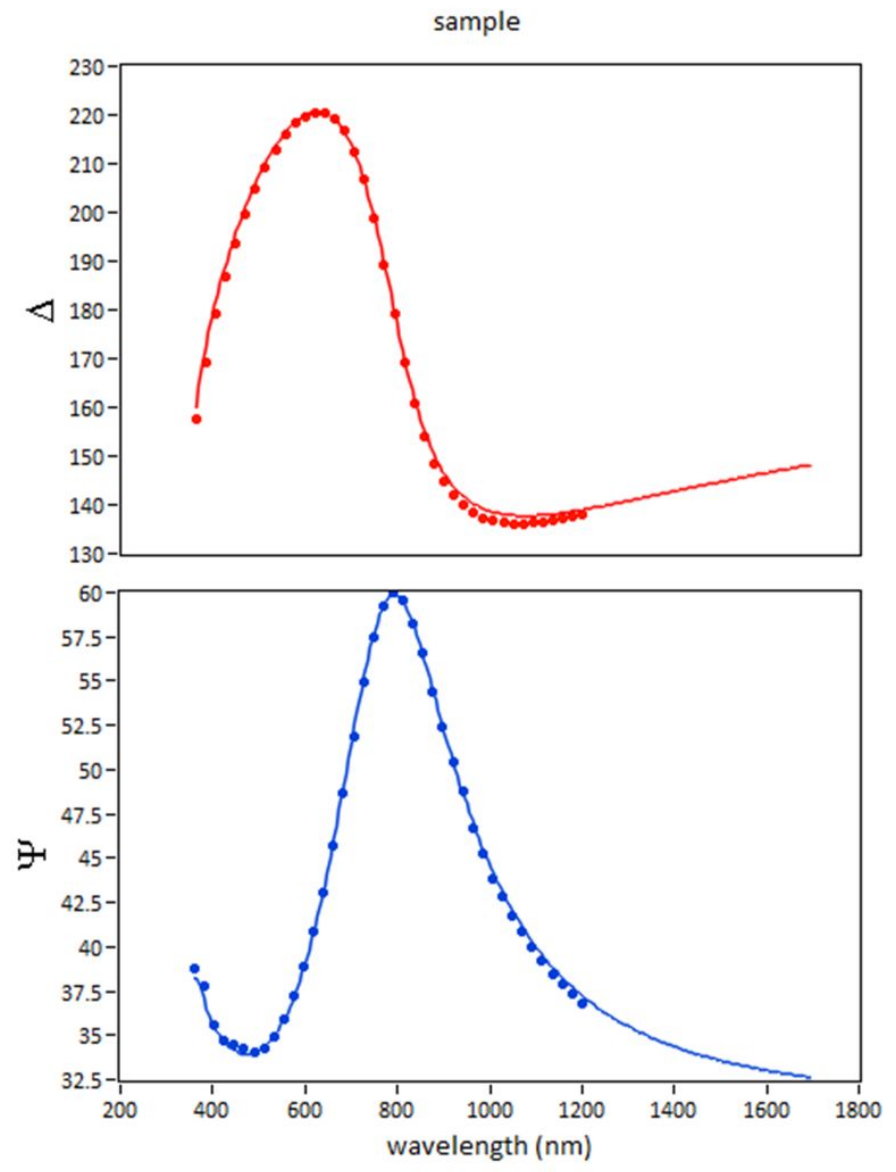

Figure S13. Representative fitting of ellipsometry curves. The film thickness as calculated from the curves was $155.9 \pm 10.9 \mathrm{~nm}$ and an RI of 1.42 .

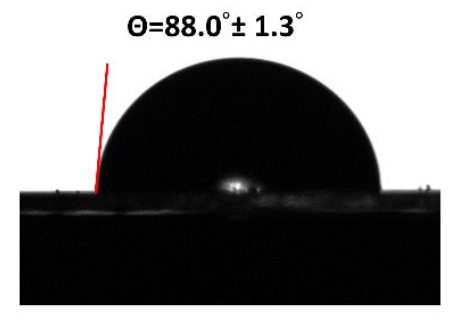

Blank-TPU

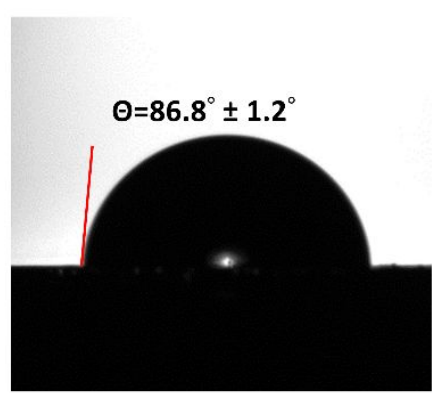

Phys-TPU

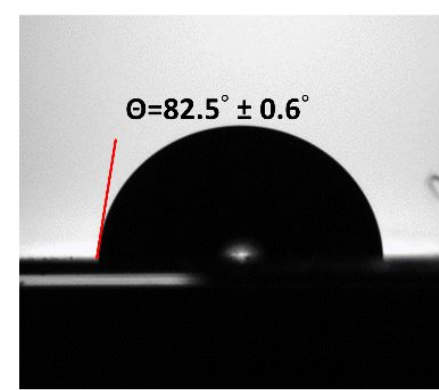

Zwitterion-TPU

Figure S14. Representative contact angle images for Blank-TPU, Physical-TPU, Zwitterion-TPU are shown. 
Table S1. Contact angle results summary

\begin{tabular}{c|c|c}
\hline Blank-TPU & Physical-TPU & Zwitterion-TPU \\
\hline $88.0 \pm 1.3$ & $86.8 \pm 1.2$ & $82.5 \pm 1.4$ \\
\hline
\end{tabular}

Table S2. QCM measurement results summary

\begin{tabular}{c|c|c} 
& Frequency recovery & Fibrinogen Adsorbed $\left(\mathrm{ng} / \mathrm{cm}^{2}\right)$ \\
\hline Blank-TPU & $9.73 \pm 9.92 \%$ & $114.5 \pm 25.1$ \\
Physical-TPU & $5.91 \pm 2.88 \%$ & $66.8 \pm 7.4$ \\
Zwitterion-TPU & $97.19 \pm 35.91 \%$ & $7.81 \pm 2.1$ \\
\hline
\end{tabular}

Table S3. Uniaxial Tensile Testing Summary

\begin{tabular}{l|c|c|c}
\hline & 0\%Allyl-TPU & Allyl-TPU & Zwitterion-TPU \\
\hline Modulus (MPa) & $2.87 \pm 0.05$ & $2.96 \pm 0.61$ & $2.63 \pm 0.55$ \\
\%Strain at Break & $1305.0 \pm 124.9$ & $1024.5 \pm 128.7$ & $1036.2 \pm 263$ \\
\hline
\end{tabular}

No statistical differences were found between groups. The statistical analysis was performed using by Tukey's test and Leven's test in Origin $9.1(\mathrm{p}<0.05, \mathrm{n}=3)$.

Table S4. Bacterial adhesion results summary

\begin{tabular}{c|c|c|c}
\hline & Blank-TPU & Physical-TPU & Zwitterion-TPU \\
\hline E. coli & $3.1 \pm 0.5 \times 10^{5}$ & $2.6 \pm 0.3 \times 10^{5}$ & $3.8 \pm 0.7 \times 10^{4}$ \\
S. epidermidis & $1.4 \pm 0.2 \times 10^{5}$ & $1.3 \pm 0.1 \times 10^{5}$ & $1.1 \pm 0.3 \times 10^{4}$ \\
\hline
\end{tabular}

Table S5. Biomass accumulation results summary

\begin{tabular}{c|c|c|c}
\hline & Blank-TPU & Physical-TPU & Zwitterion-TPU \\
\hline P. aeruginosa & $100 \pm 16.7 \%$ & $96.1 \pm 15.0 \%$ & $61.6 \pm 11.3 \%$ \\
S. epidermidis & $100 \pm 9.2 \%$ & $93.7 \pm 20.9 \%$ & $49.2 \pm 18.6 \%$ \\
\hline
\end{tabular}

